\title{
Oral anticoagulants for prevention of stroke in atrial fibrillation: systematic review, network meta-analysis, and cost effectiveness analysis
}

\author{
José A López-López, ${ }^{1}$ Jonathan A C Sterne, ${ }^{1,2}$ Howard H Z Thom, ${ }^{1}$ Julian P T Higgins, ${ }^{1,2}$ \\ Aroon D Hingorani, ${ }^{3}$ George N Okoli, ${ }^{1}$ Philippa A Davies, ${ }^{1,4}$ Pritesh N Bodalia, ${ }^{5,6}$ Peter A Bryden, ${ }^{1}$ \\ Nicky J Welton, ${ }^{1,2}$ William Hollingworth, ${ }^{1}$ Deborah M Caldwell, ${ }^{1}$ Jelena Savović, ${ }^{1,4}$ Sofia Dias, ${ }^{1}$ \\ Chris Salisbury, ${ }^{1}$ Diane Eaton, ${ }^{7}$ Annya Stephens-Boal, ${ }^{8}$ Reecha Sofat ${ }^{3}$
}

For numbered affiliations see end of article.

Correspondence to: J A C Sterne jonathan.sterne@bristol.ac.uk Additional material is published online only. To view please visit the journal online.

Cite this as: BMJ 2017;359:j5058 http://dx.doi.org/10.1136/bmj.j5058

Accepted: 24 October 2017

\section{ABSTRACT}

OBJECTIVE

To compare the efficacy, safety, and cost effectiveness of direct acting oral anticoagulants (DOACs) for patients with atrial fibrillation.

DESIGN

Systematic review, network meta-analysis, and cost effectiveness analysis.

\begin{abstract}
DATA SOURCES
Medline, PreMedline, Embase, and The Cochrane Library.

ELIGIBILITY CRITERIA FOR SELECTING STUDIES

Published randomised trials evaluating the use of a DOAC, vitamin $\mathrm{K}$ antagonist, or antiplatelet drug for prevention of stroke in patients with atrial fibrillation. RESULTS

23 randomised trials involving 94656 patients were analysed: 13 compared a DOAC with warfarin dosed to achieve a target INR of 2.0-3.0. Apixaban $5 \mathrm{mg}$ twice daily (odds ratio $0.79,95 \%$ confidence interval 0.66 to 0.94$)$, dabigatran $150 \mathrm{mg}$ twice daily $(0.65,0.52$ to 0.81$)$, edoxaban $60 \mathrm{mg}$ once daily $(0.86,0.74$ to 1.01$)$, and rivaroxaban $20 \mathrm{mg}$ once daily $(0.88,0.74$ to 1.03$)$ reduced the risk of stroke or systemic embolism compared with warfarin. The risk of stroke or systemic embolism was higher with edoxaban $60 \mathrm{mg}$ once daily $(1.33,1.02$ to 1.75$)$ and
\end{abstract}

\section{WHAT IS ALREADY KNOWN ON THIS TOPIC}

Anticoagulants have an established role in the prevention of stroke in patients with atrial fibrillation

Direct acting oral anticoagulants (DOACs) overcome some of the limitations of warfarin which include monitoring, slow onset of action, bridging, and multiple drug interactions

Randomised controlled trials, and meta-analyses of these trials, suggest that DOACs, as a class, reduce the risk of stroke or systemic embolic events compared with warfarin, and that they may be safer with respect to the risk of bleeding

\section{WHAT THIS STUDY ADDS}

DOACs, as a class, reduce the risk of stroke and all-cause mortality in patients with atrial fibrillation, and are safer with respect to major and intracranial bleeding than warfarin when used at doses to maintain an international normalised ratio (INR) of 2.0-3.0

Our cost effectiveness analysis provides evidence that, despite their higher costs, several DOACs are preferable to warfarin

We found that apixaban $5 \mathrm{mg}$ twice daily has the highest expected incremental net benefit, followed by rivaroxaban $20 \mathrm{mg}$ once daily, edoxaban $60 \mathrm{mg}$ once daily, and dabigatran $150 \mathrm{mg}$ twice daily rivaroxaban $20 \mathrm{mg}$ once daily $(1.35,1.03$ to 1.78$)$ than with dabigatran $150 \mathrm{mg}$ twice daily. The risk of all-cause mortality was lower with all DOACs than with warfarin. Apixaban $5 \mathrm{mg}$ twice daily $(0.71,0.61$ to 0.81$)$, dabigatran $110 \mathrm{mg}$ twice daily $(0.80,0.69$ to 0.93$)$, edoxaban $30 \mathrm{mg}$ once daily $(0.46,0.40$ to $0.54)$, and edoxaban $60 \mathrm{mg}$ once daily $(0.78,0.69$ to 0.90 ) reduced the risk of major bleeding compared with warfarin. The risk of major bleeding was higher with dabigatran $150 \mathrm{mg}$ twice daily than apixaban 5 $\mathrm{mg}$ twice daily $(1.33,1.09$ to 1.62$)$, rivaroxaban 20 $\mathrm{mg}$ twice daily than apixaban $5 \mathrm{mg}$ twice daily (1.45, 1.19 to 1.78 ), and rivaroxaban $20 \mathrm{mg}$ twice daily than edoxaban $60 \mathrm{mg}$ once daily $(1.31,1.07$ to 1.59$)$. The risk of intracranial bleeding was substantially lower for most DOACs compared with warfarin, whereas the risk of gastrointestinal bleeding was higher with some DOACs than warfarin. Apixaban $5 \mathrm{mg}$ twice daily was ranked the highest for most outcomes, and was cost effective compared with warfarin.

\section{CONCLUSIONS}

The network meta-analysis informs the choice of DOACs for prevention of stroke in patients with atrial fibrillation. Several DOACs are of net benefit compared with warfarin. A trial directly comparing DOACs would overcome the need for indirect comparisons to be made through network meta-analysis.

SYSTEMATIC REVIEW REGISTRATION PROSPERO CRD 42013005324.

\section{Introduction}

The prevalence of atrial fibrillation roughly doubles with each decade of age, rising to almost $9 \%$ at 80 90 years. $^{1-3}$ Atrial fibrillation increases the risk of thromboembolic stroke fivefold, as a result of blood pooling in the left atrium and systemic embolisation to the brain. More than a fifth of the 130000 annual strokes in England and Wales are attributed to atrial fibrillation (annual incidence of 114 in 100000). ${ }^{4}$ Patients with thromboembolic stroke from atrial fibrillation have higher mortality, higher morbidity, and longer hospital stays than patients with other stroke subtypes. ${ }^{1}$

The oral anticoagulant warfarin, a vitamin $\mathrm{K}$ antagonist, is effective for prevention of stroke in patients with atrial fibrillation. ${ }^{5}$ However, bleeding associated with warfarin is among the top five reasons for hospital stays, secondary to adverse drug effects, in England. ${ }^{6}$ Warfarin has a narrow therapeutic 
index as well as problematic drug and dietary interactions. The international normalised ratio (INR) requires monitoring (through hospital, primary care, anticoagulation clinics based in pharmacies, or by home monitoring with clinic support) to ensure optimal warfarin efficacy while limiting the risk of bleeding. Such monitoring is a large proportion of the overall cost of warfarin use, estimated at $£ 90$ million annually in the National Health Service (NHS) in England, Wales, and Northern Ireland. ${ }^{7}$ Because of its perceived risk and inconvenience warfarin is underused, particularly in those at high risk of stroke. ${ }^{8}$ It is estimated that only $46 \%$ of those who should be on warfarin are receiving it, with up to $40 \%$ of these not in the optimal therapeutic range of 2.0-3.0 INR units. ${ }^{7}$

Direct acting (non-vitamin $\mathrm{K}$ antagonist) oral anticoagulants (DOACs) overcome some of the limitations of warfarin, offering important benefits that can improve quality of life for patients and their carers. The class includes factor II inhibitors (eg, dabigatran) and factor Xa inhibitors (eg, apixaban, betrixaban, edoxaban, and rivaroxaban). DOACs do not require monitoring, have a more predictable pharmacokinetic (dosing) profile, and have fewer interactions with other drugs. Furthermore, they have rapid onset and offset of action, avoiding loading and use of low molecular weight heparin (LMWH) for bridging. However, their cost is substantially higher than that of warfarin and will remain so until market exclusivity periods end and generic products become available (indicative dates 2022, 2018, 2023, and 2020 for apixaban, dabigatran, edoxaban, and rivaroxaban respectively). Potential limitations of DOACs include class specific or drug specific cautions and contraindications, potential for subtherapeutic dosing, reduced adherence owing to lack of regular monitoring, absence of (or limited experience with) drug products to reverse the anticoagulant effects, the cost of maintaining stocks of different anticoagulants, and the potential for prescribing errors owing to unfamiliarity. ${ }^{9}$

Systematic reviews of randomised trials of DOACs have concluded that they have a similar efficacy to warfarin but may have some advantages with respect to the risk of bleeding. ${ }^{10-12}$ The DOACs have also been evaluated individually by the National Institute for Health and Care Excellence (NICE), and the respective technology appraisals have recommended their use. ${ }^{7}$ However, no trials have directly compared different DOACs with each other, so it is difficult to determine which drug should be recommended as a first choice for most patients. It also remains unclear whether the higher costs of DOACs are offset by improved efficacy benefits or a reduced need for therapeutic monitoring, or both. In addition, the effects of DOACs may have been overestimated in clinical trials because some patients randomised to warfarin were not maintained within the therapeutic INR target of $2 \cdot 0-3.0 .^{13-15} \mathrm{We}$ conducted a systematic review, network meta-analysis, and cost effectiveness analysis to compare DOACs with each other and with warfarin for prevention of stroke in patients with atrial fibrillation, and recommend a rank order based on efficacy, safety, and cost.

\section{Methods}

\section{Study eligibility and selection}

Our systematic review was prospectively registered with the National Institute for Health Research prospective register. Methods were in accordance with guidelines of the University of York Centre for Reviews and Dissemination ${ }^{16}$ and Cochrane. ${ }^{17}$ A detailed report of the methods and results is available elsewhere. ${ }^{18}$

We included phase II or phase III randomised controlled trials using either a superiority or noninferiority design, that evaluated the use of a direct acting oral anticoagulant (DOAC), vitamin $\mathrm{K}$ antagonist, or antiplatelet agent for prevention of stroke in patients with atrial fibrillation. We included adults with non-valvular atrial fibrillation eligible for oral anticoagulation. Trials in participants only eligible for parenteral anticoagulation were excluded. Unless otherwise specified, anticoagulation services may have been delivered in hospital, primary care, or pharmacy based clinics or through home monitoring and telephone support. The review was not limited to NHS anticoagulation services.

We focused on five DOACs; four direct factor Xa inhibitors: apixaban, betrixaban, edoxaban, and rivaroxaban, and one direct factor II (thrombin) inhibitor; dabigatran. The following direct factor Xa inhibitors were excluded: eribaxaban because the current stage of development was unclear; otamixaban because it is administered parenterally; darexaban (YM150) because it has been discontinued; and LY517717 and letaxaban (TAK442) because no information on any further clinical development was available. Two factor II inhibitors were also excluded: ximelagatran because it has been withdrawn as a result of liver toxicity and AZD0837 because it has been discontinued. Furthermore, we excluded trials comparing only different doses of the same drug, trials reporting only short term follow-up data (less than three months), trials of warfarin with target INR of 2.0 or less, and one trial that included only patients who were without thrombogenic characteristics as detected using transoesophageal echocardiography.

To determine the comparator interventions, we constructed network plots to ensure they would provide information on the relative effectiveness of the DOACs of interest. Comparators were therapeutic doses of warfarin or other vitamin $\mathrm{K}$ antagonist (with optimal INR range 2.0-4.0), as well as aspirin and clopidogrel. We excluded studies evaluating a fixed dose of warfarin, and where warfarin administration for all patients had suboptimal target INR compared with UK guidelines (INR 2.0-3.0).

The main outcomes of our interest were decided from the network meta-analyses and chosen based on three considerations: ${ }^{1}$ their clinical importance; ${ }^{2}$ the consistency of reporting across studies included in the network; and the amount of data available for inclusion in network meta-analysis. ${ }^{3}$ Outcomes 
extracted included all stroke, stroke or systemic embolism, ischaemic stroke, haemorrhagic stroke, myocardial infarction, all-cause mortality, all bleeding, minor bleeding, major bleeding, intracranial bleeding, gastrointestinal bleeding, and clinically relevant bleeding. Where necessary we derived numbers of compound events from components reported in trial publications.

We screened the studies included in previously published network meta-analysis of DOACs against our eligibility criteria. We developed searches to identify additional studies published from 2010 onwards, implemented in Medline (see web appendix 1), PreMedline, Embase, and The Cochrane Library. We also searched the NHS Economic Evaluation Database and NICE Technology Appraisals, within The Cochrane Library. We applied no restrictions on language. We sought information on studies in progress, unpublished research, or research reported in the grey literature and searched ClinicalTrials.gov (to August 2016). We screened reference lists of retrieved studies and relevant review articles.

Collection of data and assessment of the risk of bias Two members of the review team independently screened titles and abstracts. We assessed full texts of all potentially relevant reports for inclusion, having collated multiple reports from the same studies. We extracted the following data: study details (identifier, study design, location, year, length of follow-up, and industry sponsorship); participant details (number of participants, age, and sex); intervention details (drug name, dose, and timing); comparator details; details relevant to the risk of bias assessment (including adherence to and withdrawal from randomised allocation); and effect modifiers. Multiple reports from a study informed a single data extraction form. We extracted dichotomous data as number of events in intervention and control groups and numbers of participants, and we sought details of follow-up time. We also extracted estimates of hazard ratios and their confidence intervals where available. We extracted intention to treat data where these were reported. Otherwise we extracted the data as reported (often a modified intention to treat based on, eg, all patients who received at least one dose of the study drug).

Data extraction and risk of bias assessments using the Cochrane tool were carried out by one reviewer (GNO) in a Microsoft Access data collection form, and checked by a second reviewer (PB). ${ }^{19}$ Disagreements were resolved by consensus or by referral to a third reviewer (PAD or JS) where necessary.

\section{Data synthesis and statistical analysis}

We generated network plots of comparisons to illustrate which interventions had been compared within randomised trials (direct comparisons). Different doses or frequencies of administration (once daily or twice daily) of DOACs were analysed separately and hence appear as separate points in network plots. We defined two independent nodes for warfarin interventions, labelled as warfarin (INR 2.0-3.0) and warfarin (INR 3.0-4.0) respectively. The first of these formed the reference treatment across all networks. We also included in warfarin (INR 2.0-3.0) some interventions with an INR range of 2.5-3.5 or 2.0-4.5. In some trials the INR range for some patients in the warfarin arm was subtherapeutic (below 2.0), so that the total INR range was 1.6-3.0. These interventions were excluded from the main analysis, but merged with the INR 2.03.0 node in a sensitivity analysis.

We considered two separate nodes for antiplatelets, less than $150 \mathrm{mg}$ once daily and $150 \mathrm{mg}$ or more once daily. The dose range considered in the AVERROES ${ }^{20}$ trial (81-324 mg once daily) was much wider than in any other trial, and we included this intervention in the lower dose node ( $<150 \mathrm{mg}$ once daily) because some patients from that study had received a low daily dose. As a sensitivity analysis, we excluded the AVERROES trial from the network.

Where outcome data were presented for multiple time points, we took the longest period of followup. For stroke or systemic embolism, we used the total number of stroke events if the former was not reported. When clinically relevant bleeding was not reported, we calculated it as the sum of the major bleeding and clinically relevant non-major bleeding events.

In the primary network meta-analyses, we treated data as binomial, modelling the number of events out of the total number of participants using a logistic model. We omitted trials with no events in any arm and where there were events in at least one arm of a trial but no events in one or more other arms, we added 0.5 events to all cells in the $2 \times 2$ table for that trial. As sensitivity analyses, we also undertook separate analyses for all outcomes where we took into account the different follow-up periods and the different reporting patterns considered across studies (see web appendix 3 and 4).

We conducted both standard meta-analyses of each pairwise direct comparison between interventions, and a network meta-analysis combining results of all these comparisons in one analysis, exploiting both the direct comparisons within trials and the indirect comparisons across trials for each outcome. The network meta-analyses used a logistic regression approach, implemented in a Bayesian framework using WinBUGS software (version 1.4.3). ${ }^{21}$ We used a fixed effect model, because the number of studies for each comparison was small. We present results as odds ratios with 95\% confidence intervals and as rankograms displaying the probability that each intervention evaluated in phase III trials is ranked highest, second highest, and so on, for preventing each outcome. To assess consistency among sources of evidence, we back calculated the indirect comparisons of interventions from the network meta-analysis results and the direct comparisons. We first tabulated intervention effects for each DOAC against warfarin (mostly based on direct comparisons), and then 
comparisons, derived from the network meta-analysis, between the DOAC dosing strategies that had been evaluated in a phase III trial.

We prespecified important characteristics to be age, sex, ethnicity or race, body mass index or weight, renal status or creatinine clearance, blood pressure, diabetes mellitus, hypertension, previous thrombotic event, liver disease, chronic heart failure, cancer, pregnancy, intervention dose, mean time in warfarin therapeutic range, $\mathrm{CHADS}_{2}$ score, $\mathrm{CHA}_{2} \mathrm{DS}_{2}$-VASc score, HAS-BLED score, history of previous stroke or transient ischaemic attack, previous myocardial infarction, and summary assessment of the risk of bias for each outcome. We used meta-regression to determine the influence of these potential effect modifiers.

\section{Cost effectiveness analysis}

We evaluated the most cost effective first-line (initially used) anticoagulant for the prevention of ischaemic stroke in patients with atrial fibrillation, from the perspective of the UK National Health Service (NHS). Only recommended doses were considered. Betrixaban was excluded from this analysis because of insufficiently precise evidence regarding efficacy. The base case was a cohort aged 70, modelled to the end of life. We used a discrete time Markov multistate model, with a cycle length of three months. ${ }^{22}$ The main assumptions and structure of the model are provided in web appendix 2. We estimated expected lifetime total costs and quality adjusted life years (QALYs) for a patient with atrial fibrillation, aged 70, beginning each first-line anticoagulation strategy. We estimated the net monetary benefit for each strategy using the willingness to pay threshold of $£ 20000$ (the amount the UK NHS is willing to pay for one year of perfect health, which is one QALY). Expected incremental costs, QALYs, and net benefit for each preferred strategy compared with warfarin INR 2.03.0 were also estimated. We conducted a wide range of sensitivity analyses, described in web appendix 2 . A key sensitivity analysis explored the price at which DOACs would have to be sold to become most cost effective.

\section{Patient involvement}

Two representatives (DE and ASB) of patient group charities (AntiCoagulation Europe and Thrombosis UK) participated in the design (as co-applicants on the grant application), conduct (including attending project meetings), reporting, and interpretation of the results of this study, and are included as co-authors of this paper. It was not evaluated whether the studies included in the review had any patient involvement

\section{Results}

\section{Studies included}

Figure 1 shows how weidentified 23 completed, eligible, randomised trials involving 94656 patients (see web appendix 3 for a summary of trial characteristics). All reports were written in English except for one paper written in Chinese that was translated with assistance from a native Chinese speaker. ${ }^{23}$ Sixteen trials, involving $97 \%$ of patients, were phase III. Where reported, the mean age of included patients ranged from 63.3 to 81.5 years (median 70.0 years); proportions of male patients from $44.9 \%$ to $82.9 \%$ (63.3\%); and mean body mass index (BMI) from 24.4 to $30.5 \mathrm{~kg} / \mathrm{m}^{2}\left(28.0 \mathrm{~kg} / \mathrm{m}^{2}\right)$. The percentage of patients with previous stroke (5.0\% to $63.8 \%$, median $20.2 \%$ ), hypertension (38.0\% to $93.7 \%, 73.8 \%$ ), and chronic heart failure $(0 \%$ to $100 \%, 32 \%)$ varied across the studies. Mean time in therapeutic range for warfarin arms ranged from $45.1 \%$ to $83.0 \%$ (median $63.8 \%$ ) of the duration of treatment.

Thirteen studies (six phase III ${ }^{15}$ 24-28 and seven phase II ${ }^{13} 1429$-33) examined one of the following direct acting oral anticoagulants (DOACs): apixaban, ${ }^{24} 25$ 31 betrixaban, ${ }^{32}$ dabigatran, ${ }^{13} 2833$ edoxaban, ${ }^{14} 2629$ ${ }^{30}$ and rivaroxaban. ${ }^{15} 27$ Treatment durations ranged from three to 30 months: outcomes were reported at the end of the treatment period. Pharmaceutical companies sponsored 15 studies, including all those examining DOACs. Sponsor details were not reported in two studies. Table 1 shows the number of patients analysed and the number of events for the main outcomes reported in each trial (event counts for other outcomes are in web appendix 4).

\section{Risk of bias in included studies}

The risk of bias judgments for studies contributing to analyses of each outcome are presented in web appendix 5. Most studies were judged to be at a low or unclear risk of bias for sequence generation and at low risk of bias for allocation concealment. Most studies were open label and were judged to be at high risk of bias for blinding of participants and staff. Most studies were judged to be at low risk of bias for blinding of outcome assessment and for incomplete outcome data.

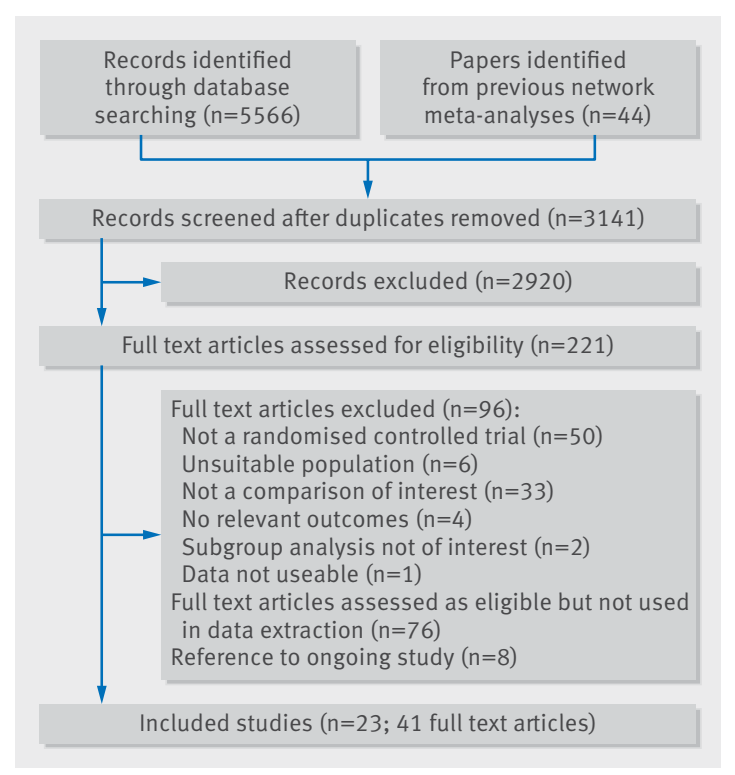

Fig 1 | PRISMA flowchart for review of prevention of stroke in patients with atrial fibrillation 


\begin{tabular}{|c|c|c|c|c|c|c|c|c|c|c|c|c|c|c|}
\hline \multirow[b]{2}{*}{ Study } & \multirow{2}{*}{$\begin{array}{l}\text { Study } \\
\text { size }^{*}\end{array}$} & \multirow{2}{*}{$\begin{array}{l}\text { Reporting } \\
\text { patternt }\end{array}$} & \multicolumn{4}{|c|}{ Stroke } & \multirow{2}{*}{$\begin{array}{l}\text { Myocardial } \\
\text { infarction }\end{array}$} & \multirow{2}{*}{$\begin{array}{l}\text { All-cause } \\
\text { mortality }\end{array}$} & \multicolumn{6}{|c|}{ Bleeding } \\
\hline & & & All & or $\mathrm{SE}$ & Ischaemic & Haemorrhagic & & & All & Minor & Major & IC & GI & $\mathrm{CR}$ \\
\hline ACTIVE W & 6706 & 1 & 159 & NA & 132 & 20 & 59 & 317 & 1199 & 1049 & 194 & NA & NA & NA \\
\hline AF-ASA-VKA-CHINA & 101 & 2 & NA & 18 & 14 & NA & 5 & 4 & 14 & 9 & 3 & NA & 1 & \\
\hline AF-DABIG-VKA-JAPAN & 166 & 2 & NA & 1 & NA & NA & NA & NA & 45 & NA & 3 & NA & NA & 14 \\
\hline AF-EDOX-VKA-ASIA & 234 & 2 & NA & 0 & NA & NA & NA & NA & 57 & 48 & 2 & NA & 1 & 11 \\
\hline AF-EDOX-VKA-JAPAN & 519 & 2 & NA & 1 & NA & NA & NA & $\mathrm{NA}$ & 115 & $\mathrm{NA}$ & 5 & NA & NA & 20 \\
\hline AF-EDOX-VKA-MULTI & 1143 & 2 & NA & 11 & NA & NA & 5 & NA & 114 & 52 & 13 & NA & NA & 62 \\
\hline AF-VKA-ASA-CHINA & 440 & 2 & 10 & NA & 9 & 1 & NA & 11 & NA & 25 & 8 & $\mathrm{NA}$ & 7 & NA \\
\hline AFASAK & 671 & 2 & 20 & NA & NA & NA & NA & 15 & 23 & NA & NA & NA & 5 & NA \\
\hline AFASAK II & 339 & 1 & 19 & 22 & 8 & 2 & 8 & 31 & NA & 68 & 9 & 3 & NA & NA \\
\hline ARISTOTLE & 18140 & 3 & 449 & 477 & 337 & 118 & 192 & 1272 & 5416 & NA & 789 & 174 & 224 & 1490 \\
\hline ARISTOTLE-J & 218 & 2 & NA & 3 & 1 & NA & 0 & 0 & 41 & 36 & 1 & NA & 1 & 6 \\
\hline AVERROES & 5599 & 1 & 154 & 164 & 128 & 15 & 52 & 251 & NA & 341 & 83 & 24 & 26 & 263 \\
\hline BAFTA & 973 & 1 & 94 & NA & NA & NA & 30 & 215 & NA & NA & 50 & NA & NA & NA \\
\hline Chinese ATAFS & 704 & 2 & 23 & NA & NA & NA & NA & 12 & NA & NA & NA & NA & NA & NA \\
\hline ENGAGE AF-TIMI 48 & 21026 & 2 & 958 & 1016 & 804 & 169 & 443 & 2349 & NA & 1851 & 1196 & 234 & 551 & 4450 \\
\hline EXPLORE-Xa & 508 & 2 & 2 & NA & 2 & NA & 0 & 2 & 118 & 109 & 8 & NA & NA & 18 \\
\hline J-ROCKET AF & 1278 & 2 & 31 & 33 & 24 & 7 & 4 & 12 & NA & NA & NA & 15 & 18 & 262 \\
\hline PATAF & 272 & 1 & 7 & NA & 7 & NA & 5 & 29 & NA & NA & NA & $\mathrm{NA}$ & 11 & NA \\
\hline PETRO & 515 & 2 & NA & 2 & NA & NA & NA & NA & 88 & NA & 4 & NA & NA & 36 \\
\hline RE-LY & 18113 & 2 & NA & 519 & 389 & 71 & 270 & 1371 & NA & 5284 & 1162 & 150 & 435 & NA \\
\hline ROCKET AF & 14236 & 2 & 405 & 575 & 310 & NA & 227 & 458 & NA & NA & 781 & 139 & 378 & 2924 \\
\hline SPAF II & 1100 & 3 & NA & 67 & 63 & NA & 34 & 127 & NA & NA & NA & 18 & NA & NA \\
\hline WASPO & 75 & 2 & 0 & NA & NA & NA & NA & 3 & NA & 10 & 3 & NA & 3 & NA \\
\hline Total & 93076 & & 2331 & 2909 & 2228 & 403 & 1334 & 6479 & 7230 & 8882 & 4314 & 757 & 1661 & 9556 \\
\hline
\end{tabular}

SE=systemic embolism; IC=intracranial; $\mathrm{Gl}=$ gastrointestinal; $\mathrm{CR}=$ clinically relevant; $\mathrm{NA}=$ not available

*Study sizes are based on the arms that were relevant to the purpose of this review.

$\dagger 1=$ Number of patients whose first event is of a given type, patients censored thereafter; $2=$ Number of patients experiencing at least one event of each given type; $3=$ Total number of events of each type.

Stroke or systemic embolism

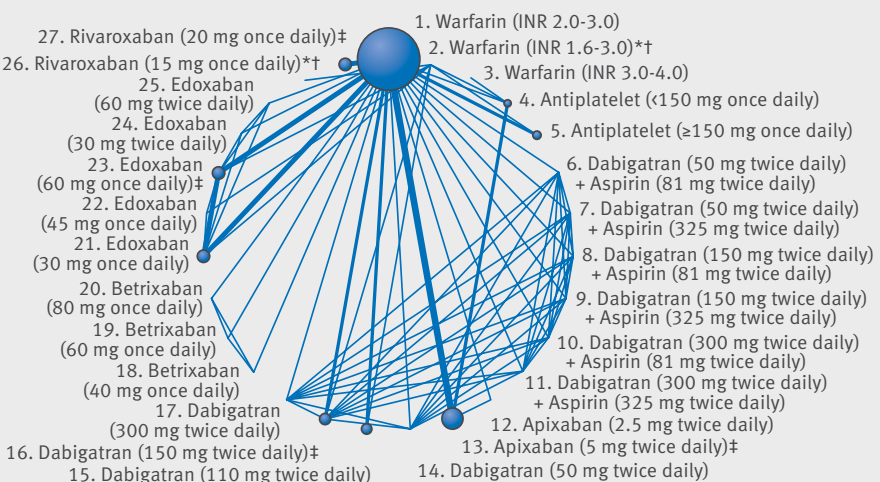

Ischaemic stroke

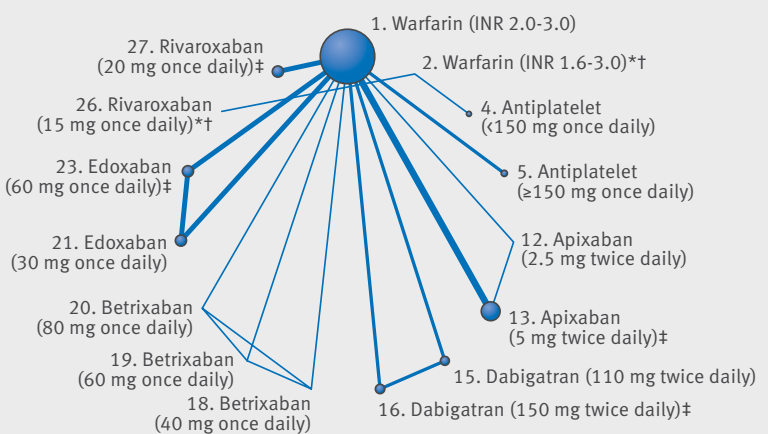

(40 mg once daily)

Fig 2 | Network plots of stroke or systemic embolism, ischaemic stroke, myocardial infarction, and all-cause mortality outcomes for review of prevention of stroke in patients with atrial fibrillation. Line thickness is proportional to the number of patients that contributed to the comparison *Doses of direct acting oral anticoagulants (DOACs) that were excluded from the primary analysis owing to not being considered to be of interest to inform health decisions in the UK (eg, warfarin interventions using subtherapeutic INR ranges), the total number of events was zero so they are uninformative, or they did not connect with the other trials in the network.

tExcluded doses of DOACs that were included in sensitivity analyses.

¥Recommended doses of DOACs evaluated in a phase III trial; these are interventions of primary interest 


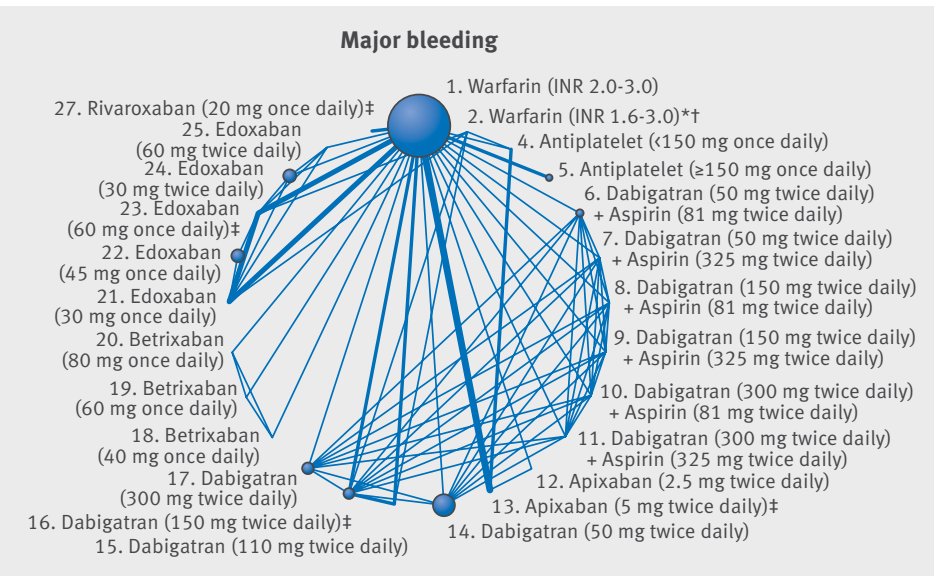

Clinically relevant bleeding

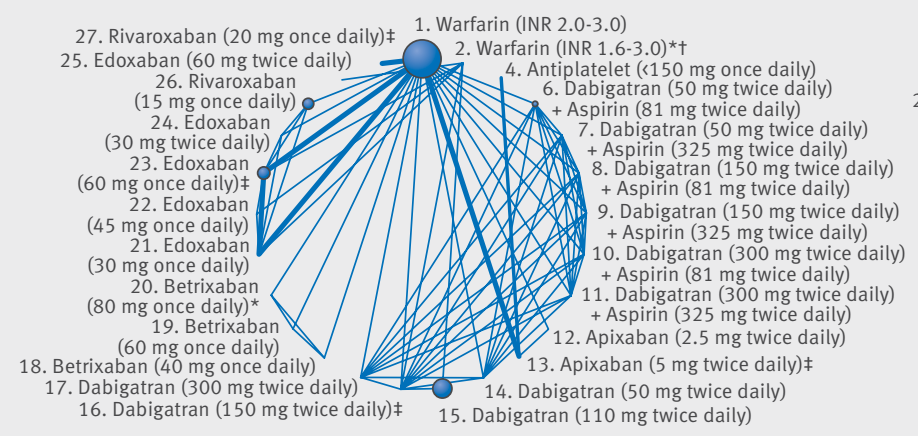

Intracranial bleeding

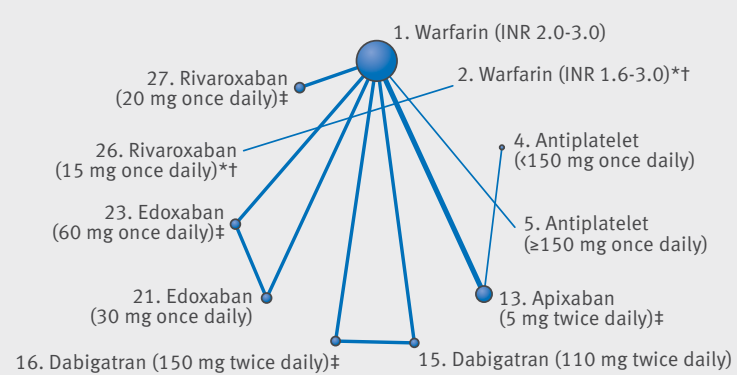

16. Dabigatran (150 $\mathrm{mg}$ twice daily)
Gastrointestinal bleeding

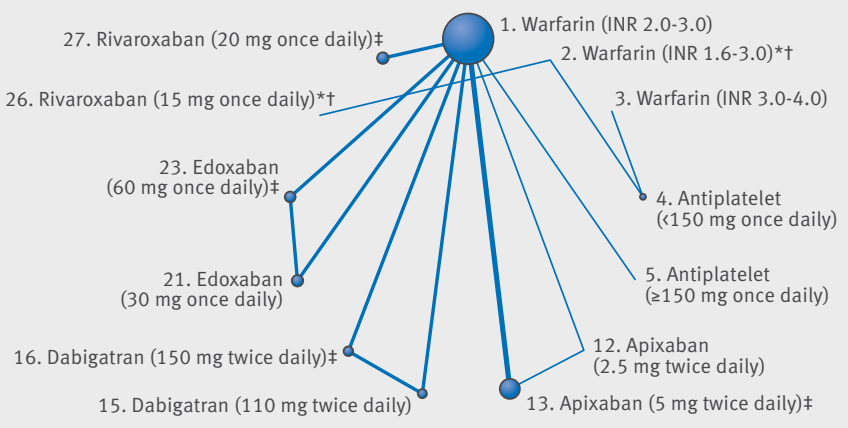

Fig 3 | Network plots of bleeding outcomes for review of prevention of stroke in patients with atrial fibrillation. Line thickness is proportional to the number of patients that contributed to the comparison

*Doses of direct acting oral anticoagulants (DOACs) that were excluded from the primary analysis owing to not being considered to be of interest to inform health decisions in the UK (eg, warfarin interventions using subtherapeutic INR ranges), the total number of events was zero so they are uninformative, or they did not connect with the other trials in the network.

tExcluded doses of DOACs that were included in sensitivity analyses.

‡Recommended doses of DOACs evaluated in a phase III trial; these are interventions of primary interest

\section{Efficacy and safety results}

A total of 27 different interventions were included in the network: the direct comparisons made for different outcomes are shown in figure 2 (efficacy outcomes) and figure 3 (safety outcomes). Table 2 shows evidence that apixaban $5 \mathrm{mg}$ twice daily (odds ratio $0.79,95 \%$ confidence interval 0.66 to 0.94 ), dabigatran $150 \mathrm{mg}$ twice daily $(0.65,0.52$ to 0.81$)$, edoxaban $60 \mathrm{mg}$ once daily (0.86, 0.74 to 1.01$)$, and rivaroxaban $20 \mathrm{mg}$ once daily $(0.88,0.74$ to 1.03$)$ all reduce the risk of stroke or systemic embolism compared with warfarin INR 2.0-3.0. The risk of ischaemic stroke was lower for dabigatran (0.76, 0.58 to 0.98$)$ but higher for antiplatelet interventions ( $<150 \mathrm{mg}$ once daily: 1.61 , 1.25 to 2.07 and $\geq 150 \mathrm{mg}$ once daily: $1.88,1.40$ to 2.51) than for warfarin INR 2.0-3.0. Comparing DOACs, there was evidence of a higher risk of stroke or systemic embolism with edoxaban $60 \mathrm{mg}$ once daily $(1.33,1.02$ to 1.75$)$ and rivaroxaban $20 \mathrm{mg}$ once daily $(1.35,1.03$ to 1.78 ) than with dabigatran $150 \mathrm{mg}$ twice daily. There was little evidence that the risk of ischaemic stroke differed between licensed strengths of DOACs.

There was weak evidence that the risk of myocardial infarction was higher with dabigatran $110 \mathrm{mg}$ twice daily (odds ratio 1.32, 95\% confidence interval 0.97 to 1.79$)$, dabigatran $150 \mathrm{mg}$ twice daily $(1.29,0.96$ to $1.75)$, and edoxaban $30 \mathrm{mg}$ once daily (1.22, 0.97 to 1.53) compared with warfarin INR 2.0-3.0. The risk of myocardial infarction was lower with rivaroxaban $20 \mathrm{mg}$ once daily (0.80, 0.61 to 1.04$)$ compared with warfarin INR 2.0-3.0. Between the DOACs, there was weak evidence that the risk of myocardial infarction was higher with dabigatran $150 \mathrm{mg}$ twice daily compared with apixaban $5 \mathrm{mg}$ twice daily $(1.48,0.98$ to 2.2 ), and lower with rivaroxaban $20 \mathrm{mg}$ once daily compared with dabigatran $150 \mathrm{mg}$ twice daily (0.62, 0.41 to 0.93 ). The risk of all-cause mortality was lower with all the DOAC interventions compared with warfarin INR 2.0-3.0: odds ratios ranged from 0.83 for rivaroxaban $20 \mathrm{mg}$ once daily $(95 \%$ confidence interval 0.69 to 1.00 ) to 0.91 for dabigatran $110 \mathrm{mg}$ twice daily (0.80 to 1.04 ) and edoxaban $60 \mathrm{mg}$ once daily ( 0.82 to 1.01). There was little evidence of differences between the effects of licensed DOACs on all-cause mortality.

Table 3 shows evidence that apixaban $5 \mathrm{mg}$ twice daily (odds ratio $0.71,95 \%$ confidence interval 0.61 to 0.81$)$, dabigatran $110 \mathrm{mg}$ twice daily $(0.80,0.69$ to 0.93), edoxaban $30 \mathrm{mg}$ once daily $(0.46,0.40$ to 0.54$)$, and edoxaban $60 \mathrm{mg}$ once daily (0.78, 0.69 to 0.90$)$ all reduce the risk of major bleeding compared with 


\begin{tabular}{|c|c|c|c|c|c|c|c|c|}
\hline & \multicolumn{2}{|c|}{ Stroke or systemic embolism } & \multicolumn{2}{|c|}{ Ischaemic stroke } & \multicolumn{2}{|c|}{ Myocardial infarction } & \multicolumn{2}{|c|}{ All-cause mortality } \\
\hline & Type* & Odds ratio $(95 \% \mathrm{Cl})$ & Type & Odds ratio $(95 \% \mathrm{Cl})$ & Type & Odds ratio $(95 \% \mathrm{Cl})$ & Type & Odds ratio $(95 \% \mathrm{Cl})$ \\
\hline \multicolumn{9}{|c|}{ Comparison with warfarin INR 2.0-3.0 } \\
\hline \multicolumn{9}{|l|}{ Antiplatelet: } \\
\hline$<150 \mathrm{mg}$ once daily & D and I & 1.88 (1.40 to 2.51$)$ & 1 & 2.52 (1.62 to 3.99$)$ & $\mathrm{D}$ and I & $1.02(0.64$ to 1.64$)$ & D and I & $1.08(0.88$ to 1.33$)$ \\
\hline$\geq 150 \mathrm{mg}$ once daily & $\mathrm{D}$ & 1.61 (1.25 to 2.07$)$ & $\mathrm{D}$ & 2.00 (1.51 to 2.67$)$ & $\mathrm{D}$ & $1.38(0.94$ to 2.03$)$ & $\mathrm{D}$ & $1.04(0.87$ to 1.25$)$ \\
\hline \multicolumn{9}{|l|}{ Apixaban: } \\
\hline $5 \mathrm{mg}$ twice daily & $\mathrm{D}$ & $0.79(0.66$ to 0.94$)$ & $\mathrm{D}$ & $0.92(0.74$ to 1.14$)$ & $\mathrm{D}$ & $0.87(0.66$ to 1.15$)$ & $\mathrm{D}$ & 0.88 (0.79 to 0.98$)$ \\
\hline \multicolumn{9}{|l|}{ Dabigatran: } \\
\hline 110 mg twice daily & $\mathrm{D}$ & $0.90(0.74$ to 1.10$)$ & $\mathrm{D}$ & $1.14(0.90$ to 1.44$)$ & $\mathrm{D}$ & $1.32(0.97$ to 1.79$)$ & D & $0.91(0.80$ to 1.04$)$ \\
\hline 150 mg twice daily & $\mathrm{D}$ & $0.65(0.52$ to 0.81$)$ & $\mathrm{D}$ & $0.76(0.58$ to 0.98$)$ & $\mathrm{D}$ & $1.29(0.96$ to 1.75$)$ & $\mathrm{D}$ & $0.88(0.77$ to 1.01$)$ \\
\hline \multicolumn{9}{|l|}{ Edoxaban: } \\
\hline $30 \mathrm{mg}$ once daily & $\mathrm{D}$ & $1.13(0.97$ to 1.32$)$ & $\mathrm{D}$ & $1.44(1.21$ to 1.71$)$ & $\mathrm{D}$ & $1.22(0.97$ to 1.53$)$ & $\mathrm{D}$ & $0.86(0.78$ to 0.96$)$ \\
\hline 60 mg once daily & $\mathrm{D}$ & $0.86(0.74$ to 1.01$)$ & $\mathrm{D}$ & 1.01 (0.84 to 1.21$)$ & $\mathrm{D}$ & $0.96(0.75$ to 1.22$)$ & $\mathrm{D}$ & 0.91 (0.82 to 1.01) \\
\hline \multicolumn{9}{|l|}{ Rivaroxaban: } \\
\hline 20 mg once daily & D & $0.88(0.74$ to 1.03$)$ & $\mathrm{D}$ & $0.93(0.74$ to 1.16$)$ & $\mathrm{D}$ & $0.80(0.61$ to 1.04$)$ & D & 0.83 (0.69 to 1.00$)$ \\
\hline \multicolumn{9}{|c|}{ Comparison between recommended doses of DOACs evaluated in a phase III trial } \\
\hline $\begin{array}{l}\text { Dabigatran } 150 \text { mg twice daily and } \\
\text { apixaban } 5 \text { mg twice daily }\end{array}$ & 1 & $0.82(0.62$ to 1.08$)$ & 1 & $0.83(0.59$ to 1.16$)$ & I & 1.48 (0.98 to 2.22$)$ & I & $1.00(0.84$ to 1.19$)$ \\
\hline $\begin{array}{l}\text { Edoxaban } 60 \mathrm{mg} \text { once daily and } \\
\text { apixaban } 5 \mathrm{mg} \text { twice daily }\end{array}$ & I & 1.09 (0.87 to 1.39$)$ & I & $1.10(0.83$ to 1.46$)$ & I & $1.10(0.76$ to 1.58$)$ & I & $1.03(0.89$ to 1.20$)$ \\
\hline $\begin{array}{l}\text { Rivaroxaban } 20 \text { mg once daily and } \\
\text { apixaban } 5 \text { mg twice daily }\end{array}$ & I & $1.11(0.87$ to 1.41$)$ & I & $1.01(0.74$ to 1.38$)$ & 1 & $0.92(0.63$ to 1.34$)$ & I & $0.94(0.76$ to 1.17$)$ \\
\hline $\begin{array}{l}\text { Edoxaban } 60 \mathrm{mg} \text { once daily and } \\
\text { dabigatran } 150 \mathrm{mg} \text { twice daily }\end{array}$ & I & $1.33(1.02$ to 1.75$)$ & I & $1.33(0.97$ to 1.83$)$ & 1 & $0.74(0.50$ to 1.09$)$ & I & $1.03(0.87$ to 1.22$)$ \\
\hline $\begin{array}{l}\text { Rivaroxaban } 20 \text { mg once daily and } \\
\text { dabigatran } 150 \text { mg twice daily }\end{array}$ & 1 & 1.35 (1.03 to 1.78$)$ & 1 & 1.22 (0.87 to 1.73$)$ & 1 & $0.62(0.41$ to 0.93$)$ & I & $0.94(0.74$ to 1.18$)$ \\
\hline $\begin{array}{l}\text { Rivaroxaban } 20 \text { mg once daily and } \\
\text { edoxaban } 60 \text { mg once daily }\end{array}$ & 1 & 1.01 (0.80 to 1.27$)$ & 1 & 0.92 (0.69 to 1.23$)$ & 1 & 0.84 (0.59 to 1.20$)$ & 1 & 0.91 (0.73 to 1.13$)$ \\
\hline
\end{tabular}

warfarin INR 2.0-3.0. Between the DOACs, there was evidence that the risk of major bleeding was higher with dabigatran $150 \mathrm{mg}$ twice daily compared with apixaban $5 \mathrm{mg}$ twice daily $(1.33,1.09$ to 1.62$)$, with rivaroxaban $20 \mathrm{mg}$ twice daily compared with apixaban $5 \mathrm{mg}$ twice daily $(1.45,1.19$ to 1.78$)$, and with rivaroxaban $20 \mathrm{mg}$ twice daily compared with edoxaban $60 \mathrm{mg}$ once daily $(1.31,1.07$ to 1.59$)$. There was strong evidence that the risk of intracranial bleeding was lower with apixaban $5 \mathrm{mg}$ twice daily, dabigatran $110 \mathrm{mg}$ twice daily, dabigatran $150 \mathrm{mg}$ twice daily, edoxaban $30 \mathrm{mg}$ once daily, edoxaban $60 \mathrm{mg}$ once daily, and rivaroxaban 20 mg once daily compared with warfarin INR 2.0-3.0. For each of these DOACs and doses, except for rivaroxaban $20 \mathrm{mg}$ once daily, the estimated relative risk reduction for intracranial bleeding was more than 50\%. There was strong evidence that the risk of intracranial bleeding was lower with apixaban $5 \mathrm{mg}$ twice daily compared with the other doses of licenced strengths of DOACs. The risk of intracranial bleeding was higher with rivaroxaban $20 \mathrm{mg}$ once daily compared with apixaban $5 \mathrm{mg}$ twice daily, dabigatran $150 \mathrm{mg}$ twice daily, and edoxaban $60 \mathrm{mg}$ once daily.

There was evidence that the risk of gastrointestinal bleeding was higher with dabigatran $150 \mathrm{mg}$ twice daily (odds ratio 1.52, 95\% confidence interval 1.20 to 1.91$)$, edoxaban $60 \mathrm{mg}$ once daily $(1.22,1.01$ to 1.49), and rivaroxaban $20 \mathrm{mg}$ once daily $(1.47,1.20$ to 1.81 ) than for warfarin INR 2.0-3.0. The risk of gastrointestinal bleeding was lower with apixaban 5 mg twice daily than with other doses of DOACS.

The risk of clinically relevant bleeding during antiplatelet therapy $<150 \mathrm{mg}$ once daily was lower than with warfarin INR 2.0-3.0 (odds ratio 0.59, 95\% confidence interval 0.45 to 0.77 ). There was evidence that the risk of clinically relevant bleeding was also lower with apixaban $5 \mathrm{mg}$ twice daily $(0.67,0.60$ to $0.75)$, edoxaban $30 \mathrm{mg}$ once daily (0.59, 0.54 to 0.64$)$, and edoxaban $60 \mathrm{mg}$ twice daily (0.84, 0.77 to 0.90$)$ than with warfarin INR 2.0-3.0. However, edoxaban $30 \mathrm{mg}$ twice daily and edoxaban $60 \mathrm{mg}$ twice daily substantially increased the risk of clinically relevant bleeding compared with warfarin INR 2.0-3.0. Between the DOACs, there was evidence that the risk of clinically relevant bleeding was higher with edoxaban $60 \mathrm{mg}$ once daily compared with apixaban $5 \mathrm{mg}$ twice daily (1.24, 1.09 to 1.42 ), rivaroxaban $20 \mathrm{mg}$ once daily compared with apixaban $5 \mathrm{mg}$ twice daily $(1.53,1.33$ to 1.75$)$, and rivaroxaban $20 \mathrm{mg}$ once daily compared with edoxaban $60 \mathrm{mg}$ once daily $(1.23,1.1$ to 1.37$)$.

In meta-regression analysis there was no evidence of effect modification owing to mean age, percentage of male patients, mean CHADS $_{2}$ score, or mean time in warfarin therapeutic range for the main outcomes (web appendix 6). There were not enough data to analyse the influence of other effect modifiers. Furthermore, we found similar results after merging the warfarin interventions where the INR range was 1.6-3.0 with the 


\begin{tabular}{|c|c|c|c|c|c|c|c|c|}
\hline & \multicolumn{2}{|l|}{ Major } & \multicolumn{2}{|c|}{ Intracranial } & \multicolumn{2}{|c|}{ Gastrointestinal } & \multicolumn{2}{|c|}{ Clinically relevant } \\
\hline & Type* & Odds ratio $(95 \% \mathrm{Cl})$ & Type & Odds ratio $(95 \% \mathrm{Cl})$ & Type & Odds ratio $(95 \% \mathrm{Cl})$ & Type & Odds ratio $(95 \% \mathrm{Cl})$ \\
\hline \multicolumn{9}{|c|}{ Comparisons with warfarin INR $2.0-3.0$} \\
\hline \multicolumn{9}{|l|}{ Antiplatelet: } \\
\hline$<150 \mathrm{mg}$ once daily & $\mathrm{D}$ and $\mathrm{I}$ & $0.75(0.52$ to 1.06$)$ & 1 & $0.50(0.21$ to 1.23$)$ & 1 & $1.03(0.46$ to 2.35$)$ & $\begin{array}{l}\mathrm{D} \\
\text { and I }\end{array}$ & 0.59 (0.45 to 0.77$)$ \\
\hline$\geq 150 \mathrm{mg}$ once daily & $\mathrm{D}$ & $1.07(0.82$ to 1.42$)$ & $\mathrm{D}$ & $0.39(0.13$ to 0.98$)$ & $\mathrm{D}$ & $1.60(0.70$ to 3.85$)$ & NA & NA \\
\hline \multicolumn{9}{|l|}{ Apixaban: } \\
\hline $5 \mathrm{mg}$ twice daily & $\mathrm{D}$ & $0.71(0.61$ to 0.81$)$ & $\mathrm{D}$ & $0.42(0.30$ to 0.58$)$ & $\mathrm{D}$ & $0.89(0.68$ to 1.15$)$ & $\mathrm{D}$ & $0.67(0.60$ to 0.75$)$ \\
\hline \multicolumn{9}{|l|}{ Dabigatran: } \\
\hline 110 mg twice daily & $\mathrm{D}$ & $0.80(0.69$ to 0.93$)$ & $\mathrm{D}$ & $0.31(0.19$ to 0.47$)$ & $\mathrm{D}$ & $1.11(0.87$ to 1.42$)$ & NA & NA \\
\hline 150 mg twice daily & $\mathrm{D}$ & $0.94(0.81$ to 1.08$)$ & $\mathrm{D}$ & $0.40(0.27$ to 0.59$)$ & $\mathrm{D}$ & $1.52(1.20$ to 1.91$)$ & $\mathrm{D}$ & $1.56(0.50$ to 5.74$)$ \\
\hline \multicolumn{9}{|l|}{ Edoxaban: } \\
\hline 30 mg once daily & $\mathrm{D}$ & $0.46(0.40$ to 0.54$)$ & $\mathrm{D}$ & $0.31(0.21$ to 0.43$)$ & $\mathrm{D}$ & $0.67(0.53$ to 0.84$)$ & $\mathrm{D}$ & $0.59(0.54$ to 0.64$)$ \\
\hline 45 mg once daily & NA & NA & NA & NA & NA & NA & $\mathrm{D}$ & $1.09(0.37,3.04)$ \\
\hline $60 \mathrm{mg}$ once daily & $\mathrm{D}$ & $0.78(0.69$ to 0.90$)$ & $\mathrm{D}$ & $0.46(0.33$ to 0.62$)$ & $\mathrm{D}$ & $1.22(1.01$ to 1.49$)$ & $\mathrm{D}$ & $0.84(0.77$ to 0.90$)$ \\
\hline 30 mg twice daily & $\mathrm{NA}$ & NA & NA & NA & NA & NA & $\mathrm{D}$ & 1.97 (1.04 to 3.67) \\
\hline 60 mg twice daily & NA & NA & $\mathrm{NA}$ & NA & NA & NA & $\mathrm{D}$ & 2.76 (1.46 to 5.17) \\
\hline \multicolumn{9}{|l|}{ Rivaroxaban: } \\
\hline 20 mg once daily & $\mathrm{D}$ & $1.03(0.89$ to 1.18$)$ & $\mathrm{D}$ & $0.65(0.46$ to 0.91$)$ & $\mathrm{D}$ & $1.47(1.20$ to 1.81$)$ & $\mathrm{D}$ & $1.03(0.95$ to 1.11$)$ \\
\hline \multicolumn{9}{|c|}{ Comparison between recommended doses of DOACs evaluated in a phase III trial } \\
\hline $\begin{array}{l}\text { Dabigatran } 150 \text { mg twice daily and } \\
\text { apixaban } 5 \text { mg twice daily }\end{array}$ & I & $1.33(1.09$ to 1.62$)$ & 1 & $0.96(0.58$ to 1.60$)$ & 1 & $1.71(1.21$ to 2.43$)$ & 1 & $2.32(0.74$ to 8.63$)$ \\
\hline $\begin{array}{l}\text { Edoxaban } 60 \text { mg once daily and } \\
\text { apixaban } 5 \text { mg twice daily }\end{array}$ & 1 & $1.11(0.92$ to 1.35$)$ & 1 & 1.09 (0.69 to 1.70$)$ & 1 & $1.38(1.00$ to 1.92$)$ & 1 & $1.24(1.09$ to 1.42$)$ \\
\hline $\begin{array}{l}\text { Rivaroxaban } 20 \text { mg once daily and } \\
\text { apixaban } 5 \text { mg twice daily }\end{array}$ & 1 & $1.45(1.19$ to 1.78$)$ & 1 & $1.55(0.97$ to 2.49$)$ & 1 & $1.66(1.19$ to 2.33$)$ & 1 & $1.53(1.33$ to 1.75$)$ \\
\hline $\begin{array}{l}\text { Edoxaban } 60 \mathrm{mg} \text { once daily and } \\
\text { dabigatran } 150 \mathrm{mg} \text { twice daily }\end{array}$ & I & $0.84(0.69$ to 1.02$)$ & 1 & $1.13(0.69$ to 1.87$)$ & 1 & 0.81 (0.60 to 1.09) & 1 & 0.54 (0.14 to 1.68$)$ \\
\hline $\begin{array}{l}\text { Rivaroxaban } 20 \text { mg once daily and } \\
\text { dabigatran } 150 \text { mg twice daily }\end{array}$ & I & $1.10(0.90$ to 1.34$)$ & 1 & 1.61 (0.96 to 2.72$)$ & 1 & 0.97 (0.71 to 1.33$)$ & 1 & 0.66 (0.18 to 2.07$)$ \\
\hline $\begin{array}{l}\text { Rivaroxaban } 20 \text { mg once daily and } \\
\text { edoxaban } 60 \text { mg once daily }\end{array}$ & 1 & $1.31(1.07$ to 1.59$)$ & 1 & $1.43(0.90$ to 2.26$)$ & I & $1.21(0.90$ to 1.60$)$ & 1 & $1.23(1.10$ to 1.37$)$ \\
\hline
\end{tabular}

reference node (warfarin INR 2.0-3.0), after excluding the unusually large dose range considered for aspirin in the AVERROES trial, and with more elaborate models taking into account the follow-up periods and reporting patterns across studies.

Figure 4 shows that apixaban $5 \mathrm{mg}$ twice daily was ranked as being the most effective intervention for several of the outcomes evaluated including stroke or systemic embolism, myocardial infarction, and all-cause mortality. It was also ranked as being the safest with lowest incidence of major and gastrointestinal bleeding. Edoxaban $60 \mathrm{mg}$ once daily was ranked second for major bleeding and all-cause mortality. Except for the outcome of all-cause mortality, rivaroxaban $20 \mathrm{mg}$ once daily was ranked lowest of the DOACs. The non-DOAC interventions (warfarin dosed to achieve an INR 2.03.0 and antiplatelet $\geq 150 \mathrm{mg}$ once daily) were ranked lowest for stroke or systemic embolism.

\section{Cost effectiveness results}

Table 4 shows that dabigatran $150 \mathrm{mg}$ twice daily had the lowest expected lifetime total cost (£23 064) for a patient aged 70 starting anticoagulation, followed by apixaban $5 \mathrm{mg}$ twice daily, edoxaban $60 \mathrm{mg}$ once daily, warfarin, and rivaroxaban $20 \mathrm{mg}$ once daily which had the highest expected lifetime total cost (£24841), although there is substantial uncertainty around these estimates. Apixaban $5 \mathrm{mg}$ twice daily had the highest expected quality adjusted life years (QALYs) (5.49), followed by rivaroxaban $20 \mathrm{mg}$ once daily (5.45), dabigatran $150 \mathrm{mg}$ twice daily (5.42), edoxaban 60 mg once daily (5.41), and warfarin (5.17), though again there is substantial uncertainty. Assuming that the UK NHS is willing to pay $£ 20000$ for each year of perfect health (one QALY), all DOACs have a positive expected incremental net benefit compared with warfarin. Apixaban $5 \mathrm{mg}$ twice daily has the highest expected incremental net benefit ( $€ 7533)$, followed by dabigatran $150 \mathrm{mg}$ twice daily (£6365), rivaroxaban $20 \mathrm{mg}$ once daily (£5279), and edoxaban $60 \mathrm{mg}$ once daily (£5212). Apixaban $5 \mathrm{mg}$ twice daily is the only DOAC for which the $95 \%$ confidence interval around incremental net benefit is positive, suggesting that apixaban is cost effective compared with warfarin. Similar results were found for the higher $£ 30000$ threshold. Uncertainty in the estimated total costs and QALYs is illustrated in the cost effectiveness plane (web appendix 7). Figure 5 shows that apixaban $5 \mathrm{mg}$ twice daily has the highest probability of being the most cost effective product for prevention of stroke in patients with atrial fibrillation of the five selected for comparison. It has a probability close to $60 \%$ in the $£ 20000-£ 30000$ range of willingness to pay, which is the range generally considered by NICE. Warfarin and edoxaban $60 \mathrm{mg}$ twice daily are unlikely to be cost effective. Sensitivity analyses, described 

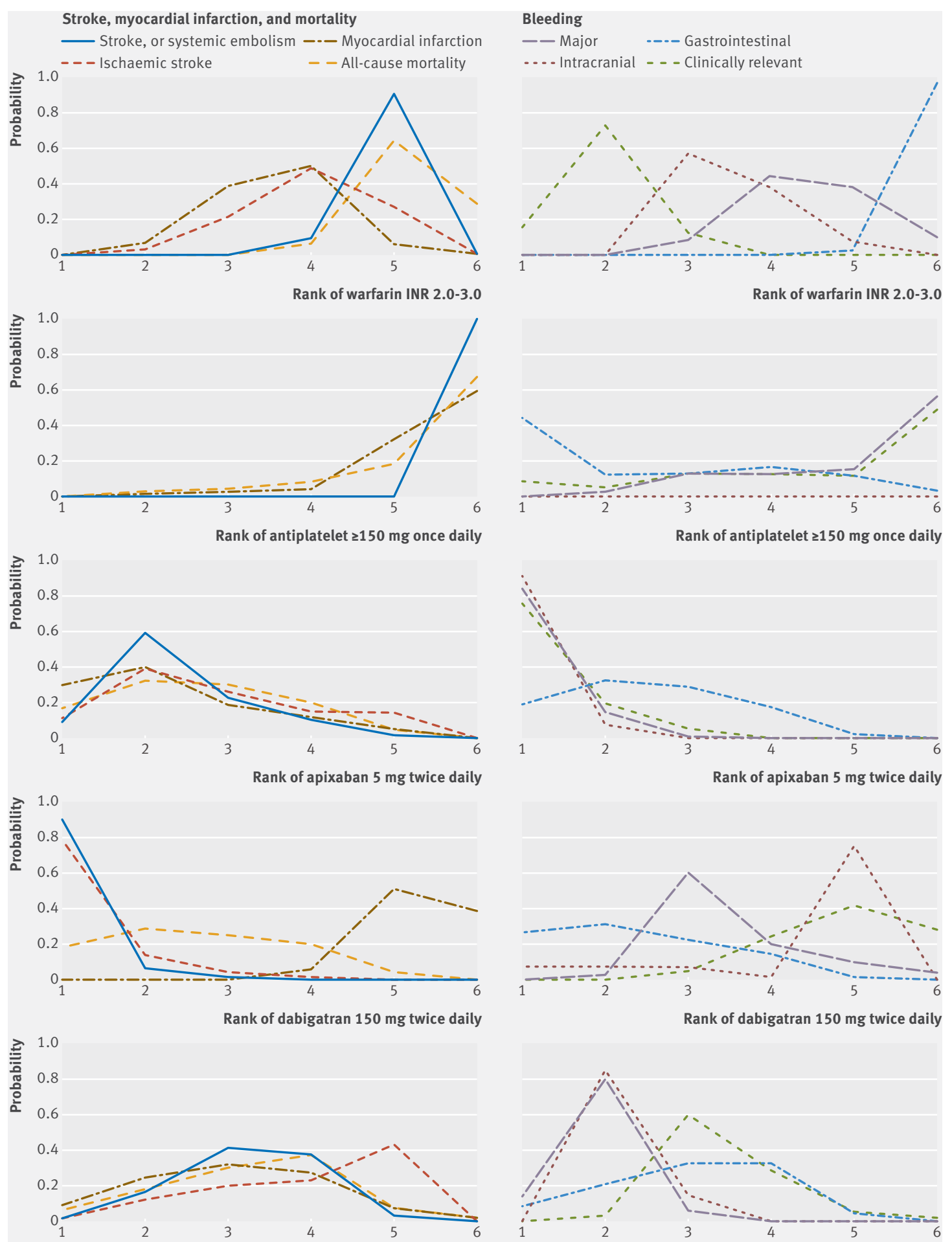

Rank of edoxaban $60 \mathrm{mg}$ once daily

Rank of edoxaban $60 \mathrm{mg}$ once daily
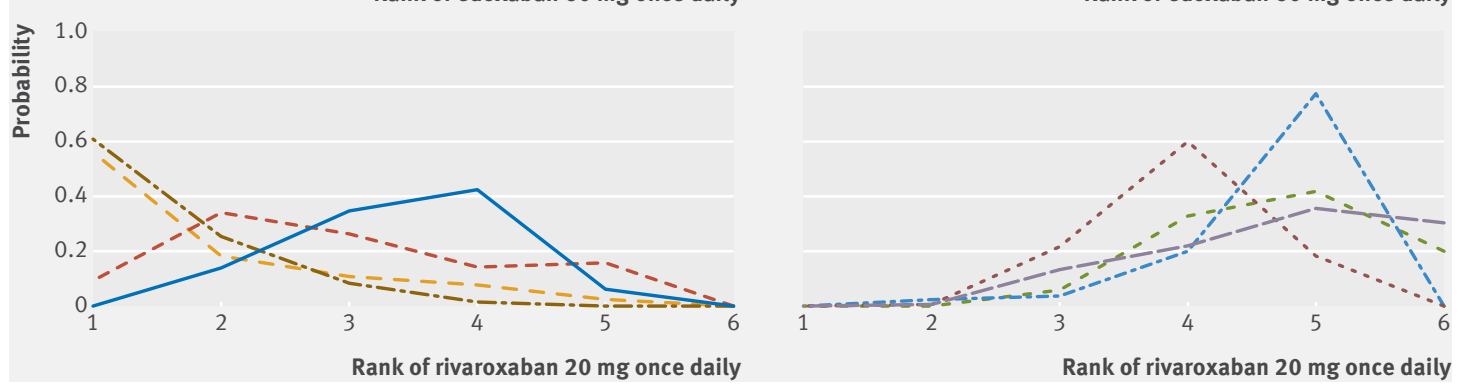

Fig 4 | Rankograms for doses of licensed products examined in prevention of stroke in patients with atrial fibrillation 


\begin{tabular}{|c|c|c|c|c|c|}
\hline \multicolumn{6}{|l|}{ Total costs $(f)$} \\
\hline Expected & $\begin{array}{l}24418(12189 \\
\text { to } 50365)\end{array}$ & $\begin{array}{l}23340(12842 \\
\text { to } 45753)\end{array}$ & $\begin{array}{l}23064(12674 \\
\text { to } 46075)\end{array}$ & $\begin{array}{l}23985(13098 \\
\text { to } 46319)\end{array}$ & $\begin{array}{l}24841(13198 \\
\text { to } 47603)\end{array}$ \\
\hline Expected incremental & NA & $\begin{array}{l}-1078(-7626 \\
\text { to } 2568)\end{array}$ & $\begin{array}{l}-1354(-8049 \\
\text { to } 2273)\end{array}$ & $\begin{array}{l}-433(-6430 \\
\text { to } 3619)\end{array}$ & $\begin{array}{l}422(-4730 \\
\text { to } 5104)\end{array}$ \\
\hline \multicolumn{6}{|l|}{ QALYS } \\
\hline Expected & $\begin{array}{l}5.166(3.629 \\
\text { to } 6.541)\end{array}$ & $\begin{array}{l}5.488(3.841 \\
\text { to } 6.795)\end{array}$ & $\begin{array}{l}5.416(3.817 \\
\text { to } 6.701)\end{array}$ & $\begin{array}{l}5.405(3.819 \\
\text { to } 6.678)\end{array}$ & $\begin{array}{l}5.451(3.824 \\
\text { to } 6.797)\end{array}$ \\
\hline Expected incremental & NA & $\begin{array}{l}0.323(-0.015 \\
\text { to } 0.814)\end{array}$ & $\begin{array}{l}0.251(-0.080 \\
\text { to } 0.703)\end{array}$ & $\begin{array}{l}0.239(-0.112 \\
\text { to } 0.684)\end{array}$ & $\begin{array}{l}0.285(-0.068 \\
\text { to } 0.810)\end{array}$ \\
\hline$£ 30000$ & NA & $\begin{array}{l}10760(576 \\
\text { to } 25861)\end{array}$ & $\begin{array}{l}8871(-597 \\
\text { to } 23402)\end{array}$ & $\begin{array}{l}7601(-1556 \\
\text { to } 20987)\end{array}$ & $\begin{array}{l}8130(-1399 \\
\text { to } 22819)\end{array}$ \\
\hline
\end{tabular}

in further detail in web appendix 2, found that these results and conclusions were robust to changes in our assumptions. Dabigatran, edoxaban, and rivaroxaban would have to be sold at the negative annual prices of $-€ 280$, -£1140, and - £1173, respectively, in order to become more cost effective than apixaban.

\section{Discussion}

To our knowledge, this is the first study of all currently licensed direct acting oral anticoagulants (DOACs) for stroke prevention in patients with atrial fibrillation that has provided a rank order for their use, in terms of both individual efficacy and safety outcomes and overall cost effectiveness. DOACs appear to be at least as effective as warfarin in reducing the risk of stroke secondary to atrial fibrillation. They are associated with a reduced risk of bleeding compared with warfarin at doses to maintain an international normalised ratio (INR) between 2.0 and 3.0, although the risk of bleeding with these drugs is still substantial and some patient populations still

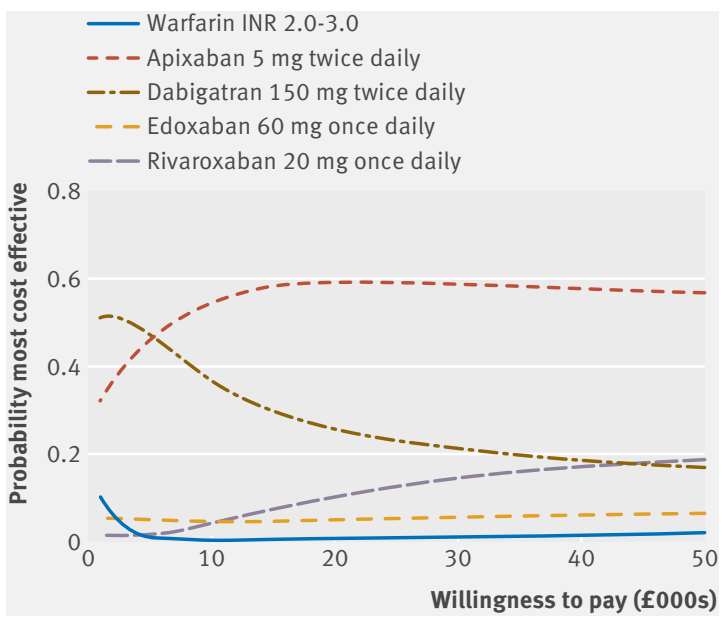

Fig 5 | Cost effectiveness acceptability curves. The probability each preferred intervention is most cost effective against willingness to pay for each QALY threshold require monitoring between DOACs, based on network meta-analyses, suggested that apixaban $5 \mathrm{mg}$ twice daily and edoxaban $60 \mathrm{mg}$ twice daily reduced the risk of major bleeding the most compared with warfarin, while maintaining efficacy in reducing the risk of stroke. This advantage of apixaban offsets its slightly higher cost compared with other DOACs and thus apixaban is associated with the highest net benefit and quality adjusted life years (QALYs) in the cost effectiveness analysis. We found no convincing evidence of effect modification owing to mean time in warfarin therapeutic range, mean age, percentage of male patients, or mean CHADS $_{2}$ score across the different outcomes.

Our study has several implications for clinical practice. Current NICE guidance does not indicate whether one drug with the same mechanism of action should be used over another. ${ }^{7}$ Providing evidence for development of prescribing guidelines is important for rational drug use, and may reduce costs of stocking multiple drugs. Our analysis indicates that, of the currently available DOACs, apixaban ranks highest on the balance of efficacy, safety, and cost. Policy makers, healthcare providers, and patients could therefore consider apixaban to be the first choice among DOACs for the prevention of stroke in most patients with atrial fibrillation, based on currently available evidence. However, clear guidance will be needed on the hierarchy of DOACs for stroke prevention in patients with atrial fibrillation, specifically a treatment hierarchy and conditions under which alternative drugs from within the same class should be prescribed (eg, as reserve treatments for patients with specific contraindications or adverse reactions to apixaban). This approach should increase the use of this drug class, benefit patient safety, and lead to eventual cost savings.

\section{Strengths and weaknesses in relation to other studies}

Our findings about the overall efficacy and safety of DOACs are consistent with previously published metaanalyses and postapproval observational studies. ${ }^{10} 12$ 
34-36 The probabilities used in our cost effectiveness analysis for outcomes including stroke, major bleeding, and all-cause mortality are also comparable to those observed in recent prospective atrial fibrillation registry studies. ${ }^{37} \mathrm{~A}$ previous review with a similar analysis approach also ranked apixaban $5 \mathrm{mg}$ twice daily and dabigatran $150 \mathrm{mg}$ twice daily as the most cost effective drugs. ${ }^{38}$ However, this previous review only included five trials, hence there was considerable uncertainty around the conclusions and some relevant drug products could not be examined.

Recent studies have suggested that the efficacy and safety of dabigatran could be improved by monitoring the achieved drug levels, because these exhibit wide interpatient variation. ${ }^{39}$ This may reduce the convenience of this DOAC and increase its cost compared with warfarin or other DOACs. A question has also been raised about the efficacy data for rivaroxaban: the largest efficacy study used an INR testing device which gave faulty readings. ${ }^{40}$ This means that a proportion of patients on warfarin may have been underdosed, inflating the relative efficacy of rivaroxaban. However, the number of patients using the INR testing device was low. The FDA have reanalysed the data to assess the impact of the faulty readings on the results and concluded that the effects on stroke or bleeding rates were minimal. ${ }^{41}$

\section{Strengths and weaknesses of this study}

The strengths of our study include comprehensive coverage of current research findings, careful appraisal of study quality, a focus on clinically relevant endpoints, and comprehensive analyses allowing comparisons between DOACs as well as comparisons of DOACs with warfarin. Limitations relate mainly to assumptions underlying the network meta-analysis and to limitations of the primary data. There were no direct comparisons between DOACs, necessitating a network meta-analysis approach. We were unable to fit random effects models because few comparisons were replicated in two or more trials. The network meta-analyses assume that studies making different comparisons do not differ in participant characteristics that are associated with response to treatment (effect modifiers). Where data were available for metaregression analyses and comparisons of direct versus indirect sources of evidence, we observed no clear evidence of effect modification.

Table 1 shows that many of the outcomes extracted for our review were incompletely reported. Such incomplete reporting reduces precision, and is a threat to the validity of results of systematic reviews if nonreporting of outcomes is influenced by the direction or statistical significance of the intervention effect. However, among the larger phase III trials comparing a DOAC with warfarin (ARISTOTLE, AVERROES, ENGAGE AF-TIMI 48, RE-LY and ROCKET AF) results for the following outcomes were all reported or could be derived from their components: stroke or systemic embolism, ischaemic stroke, myocardial infarction, all-cause mortality, major bleeding, intracranial bleeding, and gastrointestinal bleeding. This gives some reassurance that the conclusions of our review are unlikely to have been substantially affected by bias owing to selective reporting of outcomes. It is nonetheless unfortunate that the outcome of clinically relevant bleeding was not reported by RELY. Studies were generally assessed as having a low risk of bias except that most were open label so were assessed as having a high risk of bias owing to a lack of blinding.

Our findings are limited by the constraints of cost effectiveness analyses. These make long term projections on the basis of short term trial evidence, observational data, and clinically informed assumptions about treatment pathways and health state transitions. Furthermore, the profile of patients treated in trials may not be the same as those treated in practice. Older patients and those with multiple comorbidities, who may have a higher risk of bleeding than younger patients with fewer comorbidities, have been excluded from many trials. Finally, the long term safety of DOACS will only emerge as this drug class becomes more widely used in large patient populations in the future.

A head to head trial comparing different DOAC drugs would overcome the need for indirect comparisons to be made through network meta-analysis and improve the precision of estimates of relative efficacy and safety. Our cost effectiveness analyses are sensitive to these indirect comparisons, many of which are not precisely estimated. The analyses are also sensitive to costs, the effect of past events on future hazard ratios, and probabilities of treatment switching. A head to head trial would provide valuable information on these measures, although measuring all outcomes with sufficient precision would require a very large trial, which could be prohibitively expensive. Furthermore, the additional benefits and convenience for older patients and their carers are important factors to be considered.

\section{Conclusion}

DOACs appear to be at least equivalent to warfarin at preventing stroke in patients with atrial fibrillation and to carry a reduced risk of bleeding. They overcome some of the limitations associated with warfarin and may lead to increased use by patients with atrial fibrillation. The cost of anticoagulation may be greatly reduced once generic DOACs become available, since they do not require monitoring, the major cost associated with warfarin use. Despite a similar mechanism of action, apixaban at the right dose appears to maximise efficacy and safety among the DOACs, with favourable cost effectiveness. Further long term data may bring other insights with respect to safety, and it is important to identify patient groups that may not benefit from DOACs, as well as to develop drugs to reverse the anticoagulant effects of each DOAC. ${ }^{9}$ Additional investments in new trials that address limitations of the current evidence may help practitioners and policy makers better understand the role of DOACs in this clinical setting. 


\section{AUTHOR AFFILIATIONS}

${ }^{1}$ Department of Population Health Sciences, Bristol Medical School, University of Bristol, Oakfield House, Oakfield Grove, Bristol BS8 2BN, UK

${ }^{2}$ National Institute for Health Research Bristol Biomedical Research Centre, Oakfield House, Oakfield Grove, Bristol BS8 2BN, UK

${ }^{3}$ Faculty of Population Health Sciences, University College London, London, UK

${ }^{4}$ The National Institute for Health Research Collaboration for Leadership in Applied Health Research and Care West (NIHR CLAHRC West) at University Hospitals Bristol NHS Foundation Trust, Bristol, UK

${ }^{5}$ University College London Hospitals NHS Foundation Trust, London, UK

${ }^{6}$ Royal National Orthopaedic Hospital NHS Trust, London, UK

${ }^{7}$ AntiCoagulation Europe, Bromley, Kent, UK

${ }^{8}$ Thrombosis UK, Llanwrda, UK

We are grateful to Alexandra McAleenan for help with data extraction, Juan Pablo Casas and Penny Whiting for help with preparing the original grant submission, Alison Richards and Margaret Burke for help with designing and running search strategies, Sarah Dawson for help with screening titles and abstracts, and Dong Liu for help with translation of a Chinese paper.

Copyright: This work is subject to Crown Copyright.

Contributors: JACS, RS, and ADH conceived the project. GNO, PAD, PNB, and IS selected articles for inclusion, extracted data, and assessed the risk of bias. JACS, JPTH, JALL, ADH, and RS selected results for inclusion. JACS, JPTH, SD, NJW, JALL, and DMC planned the statistical analyses. JALL performed the network meta-analyses. NJW, WH, HHZT, and PAB developed and analysed the economic models. HHZT performed the cost effectiveness analyses. ADH, RS, and CS provided clinical expertise. DE and ASB provided a patient perspective. PNB provided pharmaceutical expertise. JALL, JPTH, RS, and HHZT wrote the first draft of the paper and all authors revised it critically for important intellectual content. All authors have approved this version for publication. JACS is the study guarantor.

Funding: This research was funded by the National Institute for Health Research (NIHR). Additional time from PAD was supported by the NIHR Collaboration for Leadership in Applied Health Research and Care West (CLAHRC West) at University Hospitals Bristol NHS Foundation Trust. JACS is funded by NIHR Senior Investigator award NF-SI-0611-10168. The funders were not actively involved in the research process at any stage.

Competing interests: JACS was a former member of the Health Technology Assessment Clinical Trial Board. CS is currently a Health Services and Delivery Research - Researcher Led Board member. NJW, JS, and SD report NIHR and Medical Research Council grants during the conduct of the study, outside the present work. Other authors have no potential conflicts of interest to declare.

Ethical approval: Not required.

Data sharing: No additional data are available

Transparency: The corresponding author, JACS, affirms that this manuscript is an honest, accurate, and transparent account of the study being reported; that no important aspects of the study have been omitted; and that any discrepancies from the study as planned (and, if relevant, registered) have been explained.

This is an Open Access article distributed in accordance with the terms of the Creative Commons Attribution (CC BY 4.0) license, which permits others to distribute, remix, adapt and build upon this work, for commercial use, provided the original work is properly cited. See: http://creativecommons.org/licenses/by/4.0/.

1 Kannel W, Wolf P, Benjamin E. Prevalence, incidence, prognosis, and predisposing conditions for atrial fibrillation: Population-based estimates. Am J Cardiol 1998;82(8A):2N-9N.

2 National Collaborating Centre for Chronic Conditions. Atrial fibrillation: national clinical guideline for management in primary and secondary care. Royal College of Physicians, 2006.

3 Lane DA, Skjøth F, Lip GYH, Larsen TB, Kotecha D. Temporal Trends in Incidence, Prevalence, and Mortality of Atrial Fibrillation in Primary Care. / Am Heart Assoc 2017;6:e005155. doi:10.1161/ JAHA.116.005155
4 Royal College of Physicians Sentinel Stroke National Audit Programme (SSNAP). Clinical audit April - June 2015 report prepared by Royal College of Physicians, Clinical Effectiveness and Evaluation Unit on behalf of the Intercollegiate Stroke Working Party. https://www. strokeaudit.org/Documents/National/PostAcuteOrg/2015/2015PAOrgPublicReportPhase2.asp

5 Hart RG, Benavente O, McBride R, Pearce LA. Antithrombotic therapy to prevent stroke in patients with atrial fibrillation: a meta-analysis. Ann Intern Med 1999;131:492-501. doi:10.7326/0003-4819131-7-199910050-00003

6 Pirmohamed M, James S, Meakin S. Adverse drug reactions as cause of admission to hospital: prospective analysis of 18820 patients. BM/ 2004:329:15-9. doi:10.1136/bmj.329.7456.15

7 National Institute for Health and Clinical Excellence. Atrial fibrillation: the management of atrial fibrillation (CG180). London; $2014 \mathrm{https://}$ www.nice.org.uk/guidance/cg180

8 Lee S, Shafe AC, Cowie MR. UK stroke incidence, mortality and cardiovascular risk management 1999-2008: time-trend analysis from the General Practice Research Database. BMJ Open 2011;1:e000269. doi:10.1136/bmjopen-2011-000269

9 Verheugt FW, Granger CB. Oral anticoagulants for stroke prevention in atrial fibrillation: current status, special situations, and unmet needs. Lancet 2015:386:303-10 doi:10.1016/S0140-6736(15)60245-8

10 Cope S, Clemens A, Hammès F, Noack H, Jansen JP. Critical appraisal of network meta-analyses evaluating the efficacy and safety of new oral anticoagulants in atrial fibrillation stroke prevention trials. Value Health 2015;18:234-49. doi:10.1016/j.jval.2014.10.012

11 Assiri A, Al-Majzoub O, Kanaan AO, Donovan JL, Silva M. Mixed treatment comparison meta-analysis of aspirin, warfarin, and new anticoagulants for stroke prevention in patients with nonvalvular atrial fibrillation. Clin Ther 2013;35:967-984.e2. doi:10.1016/j. clinthera.2013.05.011

12 Dogliotti A, Paolasso E, Giugliano R. Current and new oral antithrombotics in non-valvular atrial fibrillation: a network metaanalysis of 79808 patients. Heart 2014;5:396-405.doi:10.1136/ heartjnl-2013-304347

13 Boehringer Ingelheim. A dose response study of dabigatran etexilate (BIBR 1048) in pharmacodynamics and safety in patients with nonvalvular atrial fibrillation in comparison to warfarin NCT01136408. 2014. https://clinicaltrials.gov/ct2/show/NCT01136408

14 Yamashita T, Koretsune Y, Yasaka M. Randomized, multicenter, warfarin-controlled phase II study of edoxaban in Japanese patients with non-valvular atrial fibrillation. Circ / 2012;76:1840-7. doi:10.1253/circj.CJ-11-1140

15 Hori M, Matsumoto M, Tanahashi N. J-ROCKET AF study investigators Rivaroxaban vs. warfarin in Japanese patients with atrial fibrillation the J-ROCKET AF study -. Circ J 2012;76:2104-11. doi:10.1253/circj. C)-12-0454

16 Centre for Reviews and Dissemination. Systematic Reviews: CRD's Guidance for Undertaking Reviews in Health Care. 3rd ed. University of York, Centre for Reviews and Dissemination, 2009.

17 Higgins JPT, Green S. Cochrane Handbook for Systematic Reviews of Interventions. Wiley, 2008doi:10.1002/9780470712184.

18 Sterne JA, Bodalia PN, Bryden PA. Oral anticoagulants for primary prevention, treatment and secondary prevention of venous thromboembolic disease, and for prevention of stroke in atrial fibrillation: systematic review, network meta-analysis and cost effectiveness analysis. Health Technol Assess 2017;21:1-386. doi:10.3310/hta21090

19 Higgins JPT, Altman DG, Gøtzsche PC. Cochrane Bias Methods GroupCochrane Statistical Methods Group. The Cochrane Collaboration's tool for assessing risk of bias in randomised trials. BMJ 2011;343:d5928. doi:10.1136/bmi.d5928

20 Connolly SJ, Eikelboom J, Joyner C. AVERROES Steering Committee and Investigators. Apixaban in patients with atrial fibrillation. N Engl Med 2011:364:806-17. doi:10.1056/NEIMoa1007432

21 Dias S, Sutton AJ, Ades AE, Welton NJ. Evidence synthesis for decision making 2: a generalized linear modeling framework for pairwise and network meta-analysis of randomized controlled trials. Med Decis Making 2013;33:607-17. doi:10.1177/0272989X12458724

22 Kansal AR, Sorensen SV, Gani R. Cost-effectiveness of dabigatran etexilate for the prevention of stroke and systemic embolism in UK patients with atrial fibrillation. Heart 2012;98:573-8. doi:10.1136/ heartjnl-2011-300646

23 Hu DY, Zhang HP, Sun YH, Jiang LQ. Antithrombotic Therapy in Atrial Fibrillation Study Group. [The randomized study of efficiency and safety of antithrombotic therapy in nonvalvular atrial fibrillation: warfarin compared with aspirin]. Zhonghua Xin Xue Guan Bing Za Zhi 2006;34:295-8

24 Lopes RD, Alexander JH, Al-Khatib SM. ARISTOTLE Investigators. Apixaban for reduction in stroke and other ThromboemboLic events in atrial fibrillation (ARISTOTLE) trial: design and rationale. Am Heart / 2010;159:331-9. doi:10.1016/j.ahj.2009.07.035 
25 Eikelboom JW, O'Donnell M, Yusuf S. Rationale and design of AVERROES: apixaban versus acetylsalicylic acid to prevent stroke in atrial fibrillation patients who have failed or are unsuitable for vitamin K antagonist treatment. Am Heart J 2010;159:348-353.e1. doi:10.1016/j.ahj.2009.08.026

26 Ruff CT, Giugliano RP, Antman EM. Evaluation of the novel factor Xa inhibitor edoxaban compared with warfarin in patients with atrial fibrillation: design and rationale for the Effective aNticoaGulation with factor XA next GEneration in Atrial Fibrillation-Thrombolysis In Myocardial Infarction study 48 (ENGAGE AF-TIMI 48). Am Heart J 2010;160:635-641.e2. doi:10.1016/j.ahj.2010.06.042

27 Patel MR, Mahaffey KW, Garg J. ROCKET AF Investigators. Rivaroxaban versus warfarin in nonvalvular atrial fibrillation. $N$ Engl Med 2011;365:883-91. doi:10.1056/NEJMoa1009638

28 Connolly SJ, Ezekowitz MD, Yusuf S. RE-LY Steering Committee and Investigators. Dabigatran versus warfarin in patients with atrial fibrillation. N Engl J Med 2009;361:1139-51. doi:10.1056/ NEJMoa0905561

29 Chung N, Jeon HK, Lien LM. Safety of edoxaban, an oral factor X inhibitor, in Asian patients with non-valvular atrial fibrillation. Thromb Haemost 2011;105:535-44. doi:10.1160/TH10-07-0451

30 Weitz II, Connolly SJ, Patel I. Randomised, parallel-group, multicentre, multinational phase 2 study comparing edoxaban, an oral factor Xa inhibitor, with warfarin for stroke prevention in patients with atrial fibrillation. Thromb Haemost 2010;104:633-41. doi:10.1160/TH1001-0066

31 Ogawa S, Shinohara Y, Kanmuri K. Safety and efficacy of the oral direct factor $x a$ inhibitor apixaban in Japanese patients with non-valvular atrial fibrillation. -The ARISTOTLE-J study-. Circ / 2011;75:1852-9. doi:10.1253/circj.CJ-10-1183

32 Connolly SJ, Eikelboom J, Dorian P. Betrixaban compared with warfarin in patients with atrial fibrillation: results of a phase 2, randomized, dose-ranging study (Explore-Xa). Eur Heart) 2013;34:1498-505. doi:10.1093/eurheartj/eht039

33 Ezekowitz MD, Reilly PA, Nehmiz G. Dabigatran with or without concomitant aspirin compared with warfarin alone in patients with nonvalvular atrial fibrillation (PETRO Study). Am J Cardiol 2007;100:1419-26. doi:10.1016/j. amjcard.2007.06.034
34 Lin L, Lim WS, Zhou HJ. Clinical and Safety Outcomes of Oral Antithrombotics for Stroke Prevention in Atrial Fibrillation: A Systematic Review and Network Meta-analysis. J Am Med Dir Assoc 2015;16:1103.e1-19. doi:10.1016/j. jamda.2015.09.008

35 Rasmussen LH, Larsen TB, Graungaard T, Skjøth F, Lip GYH. Primary and secondary prevention with new oral anticoagulant drugs for stroke prevention in atrial fibrillation: indirect comparison analysis. BMI 2012;345:e7097. doi:10.1136/bmj.e7097

36 Potpara TS, Lip GYH. Postapproval Observational Studies of NonVitamin K Antagonist Oral Anticoagulants in Atrial Fibrillation. JAMA 2017:317:1115-6.

37 Healey JS, Oldgren J, Ezekowitz M. RE-LY Atrial Fibrillation Registry and Cohort Study Investigators. Occurrence of death and stroke in patients in 47 countries 1 year after presenting with atrial fibrillation: a cohort study. Lancet 2016;388:1161-9. doi:10.1016/S01406736(16)30968-0

38 Wells G, Coyle D, Cameron C. Safety, Effectiveness, and Cost effectiveness of New Oral Anticoagulants Compared with Warfarin in Preventing Stroke and Other Cardiovascular Events in Patients with Atrial Fibrillation. Therapeutic Review, 2012.

39 Huisman MV, Lip GYH, Diener HC, Brueckmann M, van Ryn !. Clemens A. Dabigatran etexilate for stroke prevention in patients with atrial fibrillation: resolving uncertainties in routine practice. Thromb Haemost 2012;107:838-47. doi:10.1160/ TH11-10-0718

40 Cohen D. Manufacturer failed to disclose faulty device in rivaroxaban trial. BMJ 2016;354:i5131. doi:10.1136/bmj.i5131

41 Food and Drug Administration. FDA analyses conclude that Xarelto clinical trial results were not affected by faulty monitoring device 2016 [updated 10/11/2016]. Available from: https://www.fda.gov/ Drugs/DrugSafety/ucm524678.htm.

\section{Appendix: Supplementary materials}

